\title{
Plant Production in Solar Collector Greenhouses - Influence on Yield, Energy Use Efficiency and Reduction in $\mathrm{CO}_{2}$ Emissions
}

\author{
Dennis Dannehl ${ }^{1}$, Ingo Schuch $^{1} \&$ Uwe Schmidt $^{1}$ \\ ${ }^{1}$ Humboldt-Universität zu Berlin, Faculty of Agriculture and Horticulture, Department for Crop and Animal \\ Sciences, Division Biosystems Engineering, Albrecht-Thaer-Weg 3, Berlin 14195, Germany \\ Correspondence: Dennis Dannehl, Humboldt-Universität zu Berlin, Faculty of Agriculture and Horticulture, \\ Department for Crop and Animal Sciences, Division Biosystems Engineering, Albrecht-Thaer-Weg 3, Berlin \\ 14195, Germany. Tel: 49-30-209-346-414. E-mail: Dennis.Dannehl@agrar.hu-berlin.de
}

\author{
Received: July 16, 2013 Accepted: August 22, 2013 Online Published: September 15, 2013 \\ doi:10.5539/jas.v5n10p34 URL: http://dx.doi.org/10.5539/jas.v5n10p34
}

\begin{abstract}
A semi-closed solar collector greenhouse was tested to evaluate the yield and the energy saving potential compared with a commercial greenhouse. As such, new algorithm for ventilation, carbon dioxide $\left(\mathrm{CO}_{2}\right)$ enrichment, as well as for cooling and heating purposes initiated by a heat pump, cooling fins under the roof and a low temperature storage tank were developed. This cooling system showed that the collector greenhouse can be kept longer in the closed operation mode than a commercial one resulting in high levels of $\mathrm{CO}_{2}$ concentrations, relative humidity and temperatures. Based on these conditions, the photosynthesis and associated $\mathrm{CO}_{2}$ fixations within the plant population were promoted during the experiment, resulting in a yield increase by $32 \%$. These results were realized, although the mean light interception by energy screens and finned tube heat exchangers was increased by $11 \%$ compared to the reference greenhouse. The energy use efficiency was improved by $103 \%$ when the collector greenhouse was considered as energy production facility. In this context, the energy saving per kilogram produced tomatoes in the collector greenhouse is equivalent to the combustion of high amounts of different fossil fuels, where the reduced $\mathrm{CO}_{2}$ emissions ranged between $2.32 \mathrm{~kg}$ and $4.18 \mathrm{~kg} \mathrm{CO} 2$ per $\mathrm{kg}$ produced tomatoes. The generated total heat was composed of approximately one-third of the latent heat and over two-thirds of the sensible heat, where a maximum collector efficiency factor of 0.7 was achieved.
\end{abstract}

Keywords: energy use efficiency, $\mathrm{CO}_{2}$ emission, tomato, fossil fuel, solar energy, climate change, energy saving

\section{Introduction}

Originally, producers transferred field grown tomatoes to greenhouses in order to improve yield, to reduce phytosanitary problems and to extend the harvest season. However, this substantial progress is overshadowed by the increase in fossil fuel prices, where the demand for energy used in greenhouses is significant high (Ozkan, Fert, \& Karadeniz, 2007; Rout et al., 2008). The energy consumption in Dutch greenhouses, for instance, accounts for $79 \%$ of the energy used in the agricultural sector and $7 \%$ of the total energy use in the Netherlands (Lansink \& Bezlepkin, 2003). These dimensions show that the growth of greenhouse horticulture production contributes to a large proportion of carbon dioxide $\left(\mathrm{CO}_{2}\right)$ emissions, which are jointly responsible for the predicted mean global temperature increase (WBGU, 2008). Based on these facts, scientists invested much effort into the development of approaches for using renewable energies, in order to reduce the consumption of fossil fuels for greenhouse heating. Esen and Yuksel (2013), for instance, found that various renewable energy sources such as biogas, ground and solar energy can be efficiently used to heat a greenhouse during winter conditions in eastern Turkey. They demonstrated that a combination of flat-plate water cooled solar collectors, a biogas production plant and a ground source heat pump with horizontal slinky-type ground heat exchanger can be used as a stand-alone greenhouse heating system. Near-surface and deep geothermal-energy are also important alternative sources of energy for greenhouse heating, where the utilization of deep geothermal energy is not so prevalent in Germany (Lund, Freeston, \& Boyd, 2005; Sanner, Karytsas, Mendrinos, \& Rybach, 2003). Another source of energy is the solar energy, which can be collected in heated closed-greenhouses using cold water from soil layers (De Gelder, Dieleman, Bot, \& Marcelis, 2012). After absorbing the excess heat in the greenhouse, the heat energy is stored in the aquifer, which can be reused in winter by means of a heat-pump (Bot, 2001). In this context, the solar radiation sum impinging on the earth's surface in Berlin $\left(52^{\circ} 28^{\prime} 02^{\prime \prime} \mathrm{N}, 13^{\circ} 17^{\prime} 56^{\prime \prime} \mathrm{E}\right)$ was 
3992.4 $\mathrm{MJ} \mathrm{m}^{-2}$ measured in 2011. This heat quantity per square meter is approximately equivalent to that produced by the combustion of $99.8 \mathrm{~m}^{3}$ methane, $159.8 \mathrm{~kg}$ coal, $99.8 \mathrm{~kg}$ vegetable oils, $199.6 \mathrm{~kg}$ wood pellets or 87.9 kg heating oil (Demirbas, 2004; Fassinou, Sako, Fofana, Koua, \& Toure, 2010; iwo, 2012; Telmo \& Lousada, 2011; Ulbig \& Hoburg, 2002). Assuming that the light transmission of a conventional glass-covered greenhouse is $85 \%$ (Dannehl, 2010), it can act as a solar collector, whereby large amounts of energy can be collected and stored in summer, which would be available for heating during cooler periods. Therefore, the objectives of this study were to improve the $\mathrm{CO}_{2}$ fixation within the crop, the total yield, the energy use efficiency (EUE) and an associated reduction in $\mathrm{CO}_{2}$ emissions using a semi-closed greenhouse, which was controlled by new algorithm for cooling and heating purposes initiated by a heat pump, as well as for ventilation and $\mathrm{CO}_{2}$-enrichment.

\section{Materials and Method}

\subsection{Experimental Set-Up and Calculation of the Energy Distribution, as well as Climate Parameters}

During an annual production in 2011, energy cycles and their effects on tomato plants in a conventional controlled four-span Venlo-type greenhouse (reference GH) (ground area $=307 \mathrm{~m}^{2}$, floor level heating $<17^{\circ} \mathrm{C}$, ventilation opening $>24{ }^{\circ} \mathrm{C}$, closed energy screen $<3 \mathrm{~W} \mathrm{~m}^{-2}$ ) were compared with those prevailing in a semi-closed glasshouse with new algorithm for cooling, heating, ventilation and $\mathrm{CO}_{2}$-enrichment. Both greenhouses were arranged on a north-south axis. The semi-closed greenhouse with a ground area of $307 \mathrm{~m}^{2}$ acted as solar collector, where 16 finned tube heat exchangers ( 4 per roof bar) were installed under the roof region (Figure 1). These were used for cooling processes, whereby sensible heat caused by transmitted solar energy and latent heat produced by plant transpiration were collected simultaneously. The total length of one finned tube was $21.4 \mathrm{~m}$, which was separated into 125 galvanised fins per meter of tube. The outer diameter of the core tube was $48.3 \mathrm{~mm}$ and that of the fin was $100 \mathrm{~mm}$. The thickness of one fin was $0.8 \mathrm{~mm}$. These dimensions lead to a total cooling surface of $684 \mathrm{~m}^{2}$ resulting in a ratio of 2.23 in consideration of the total cooling surface and the ground area of the greenhouse. As coolant solution it was used water containing $31 \%$ glycol (v/v), which was pumped into the finned tubes with a minimum flow temperature of $7^{\circ} \mathrm{C}$. For this cooling process and for heating processes, a system consisting of a reversible heat pump with $40 \mathrm{~kW}$ electrical power, $120 \mathrm{~kW}$ heating power and $100 \mathrm{~kW}$ cooling power, as well as one warm water tank $\left(1 \mathrm{~m}^{3}\right)$ and one cold water tank $\left(1 \mathrm{~m}^{3}\right)$ was connected to this pipe system. In this context, a maximum cooling capacity of $390 \mathrm{~W} \mathrm{~m}^{-2}$ can be achieved. While the ventilation was opened in the reference $\mathrm{GH}$ to lower the inside temperature, the cooling process in the solar collector greenhouse (collector GH) was started at a temperature of $22{ }^{\circ} \mathrm{C}$ followed by the ventilating at $29{ }^{\circ} \mathrm{C}$ to avoid plant damage. During cooling processes, large amounts of energy were collected simultaneously. The generated heat was determined using magnetic inductive heat meters with a measuring inaccuracy of $0.02 \mathrm{~K}$ and stored in a rain-water tank $\left(300 \mathrm{~m}^{3}\right)$, which is commonly used in practice for rain water storage. The tank was additionally equipped with polystyrene insulation panels to suppress heat losses. This type of energy harvesting was associated with the dehumidification of greenhouses, which was realized by the removal of water vapour by means of condensation on the cooled finned tubes. The resulting excess condensate water was removed using aluminium gutters, which were fixed below the cooling pipes (Figure 1). This water was measured automatically with a precisely operating volumetric dosing system to calculate the latent energy (1 $\mathrm{L}$ is equal to $2.49 \mathrm{MJ}$ ) and to derive the sensible energy from the total energy that was removed from the greenhouse. The collected energy dimension of this system was shown as an example for one week and expressed as the daily amount of energy per square meter ground area of the greenhouse ( $\mathrm{MJ} \mathrm{m}^{-2}$ ).

The stored thermal energy above $30^{\circ} \mathrm{C}$ was used directly for heating in the collector $\mathrm{GH}$, whereas lower water temperatures in the rain-water tank between $7{ }^{\circ} \mathrm{C}$ and $30^{\circ} \mathrm{C}$ were increased to the required level by a heat pump. At temperatures below $7{ }^{\circ} \mathrm{C}$ in the rain-water tank, a floor-level heating was used for the heat output in cooler periods. Otherwise, the heat supply in the collector $\mathrm{GH}$ was realized via heat exchanger, i.e., using tubular film blowers fixed under the channels $\left(\mathrm{set}=16^{\circ} \mathrm{C}\right.$ ) and a vegetation heating system (set $=17^{\circ} \mathrm{C}$ ). Additionally, the reference $\mathrm{GH}$ was fitted with a daily energy screen, whereas the collector $\mathrm{GH}$ was equipped beside a daily energy screen with highly aluminized energy screens in the roof and side wall regions to avoid energy losses. To improve the conditions of plant production, the carbon dioxide fumigation was applied in both greenhouses up to a level of $800 \mathrm{ppm}$ for 12 hours, starting at $6 \mathrm{AM}$. In this context, the $\mathrm{CO}_{2}$ supply was interrupted when the ventilation was opened above $10 \%$. To obtain the desired environmental conditions in both greenhouses, all the aforementioned set points for climatic conditions were controlled by different sensors arranged in the middle of the growing tomato plants and under the roof. To provide accurate values of the experimental conditions, the measurement uncertainties of the relative humidity sensors, temperature sensors and $\mathrm{CO}_{2}$ sensors were maintained as low as possible, i.e. high precision sensors were used. In this context, the measurement 
uncertainties caused by the sensors were $\pm 3 \%, 0.02 \mathrm{~K}$ and $\pm 3 \%$, respectively. Furthermore, the sensors were calibrated at regular intervals to ensure scientifically proven results. The measurements were forwarded to a central control computer and recorded every 30 seconds, where the software program for controlling the operating mode of the greenhouses was developed at the Humboldt-Universität zu Berlin.

In order to show how the different climate control strategies affect the microclimatic conditions, the mean values of microclimatic data were separately logged for each greenhouse and subsequently used to calculate the daily

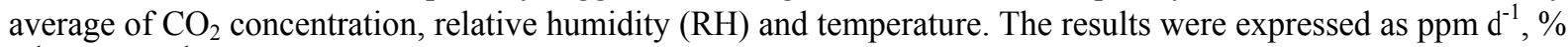
$\mathrm{d}^{-1}$ and ${ }^{\circ} \mathrm{C} \mathrm{d}{ }^{-1}$, respectively.

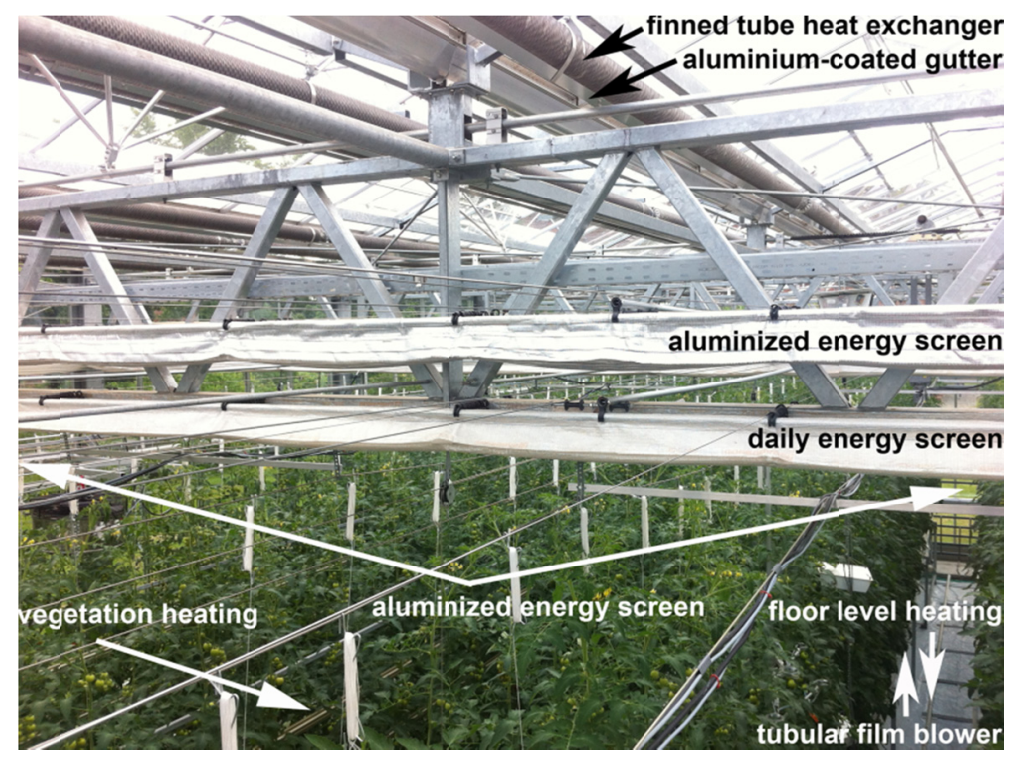

Figure 1. Equipment for cooling and heating of the solar collector greenhouse

\subsection{Yield Determination and Calculation of the Fixed $\mathrm{CO}_{2}$ Within the Tomato Crop and Light Distribution}

A net-acreage of $200 \mathrm{~m}^{2}$ per greenhouse was used to cultivate 400 tomato plants (cv. Pannovy), respectively. These were grown on the high channel in rock-wool slabs and irrigated via drip irrigation, which was controlled using light summation and by the recirculation of drain water after each irrigation cycle (set $=30 \%$ ). This study was conducted between February and October 2011. During this time, the harvested tomatoes of each plant $(\mathrm{n}=$ 400) were weighed weekly to compare the total yield $\left(\mathrm{kg} \mathrm{m}^{-2}\right)$ potential and the total number of marketable fruit in terms of both previously described climate regimes. To determine fruit quality, parts of the harvested fruit were additionally categorized into different weight classes named as A-fruit (> $70 \mathrm{~g})$, B-fruit (50-70 g), C-fruit (< $50 \mathrm{~g})$ and blossom-end rot fruit (BER). As such, 100 tomato plants $(\mathrm{n}=100)$ of each greenhouse were evaluated weekly to calculate the number of fruit of the respective weight class. At the end of the production cycle, the number of fruit of the individual quality characteristic was extrapolated to the total number of fruit, which were harvested during the whole cultivation period. The results were expressed as number of fruit per square metre.

Preliminary experiments showed that the photosynthesis can be measured with high accuracy using the Berlin Plant Response Monitoring System (BERMONIS). Under the same measurement conditions, the highest variation of photosynthesis regarding two different devices of the same type was not higher than $1.9 \%$ (Schmidt et al., 2013). In the present study, ten leaf cuvettes per greenhouse were fixed at different heights in the canopy to measure the photosynthesis every 30 seconds as $\mathrm{CO}_{2}$-gas exchange $\left(\mathrm{GECO}_{2}\right)$ using the leaf cuvette based gas exchange system BERMONIS. As such, the volumetric flow rate of the air $(\mathrm{Q})$, the $\mathrm{CO}_{2}$ level difference between ambient air and the air in the chamber $\left(\mathrm{DiffCO}_{2}\right)$, the atmospheric pressure $(\mathrm{p})$, the chamber area $(\mathrm{ChA})$, the air temperature $\left(\mathrm{T}_{\mathrm{AIR}}\right)$ and a constant (29.93), derived from the molar mass and the specific gas constant of $\mathrm{CO}_{2}$, were used to calculate $\mathrm{GECO}_{2}$ (Equation 1). The amount of the $\mathrm{GECO}_{2}$ was generated daily excluding all dissimilation processes. To evaluate the fixed $\mathrm{CO}_{2}$ within the tomato crop, the daily quantity of the $\mathrm{GECO}_{2}$, the leaf area index for the respective greenhouse and the molar mass of $\mathrm{CO}_{2}$ were included in the calculations. The results were plotted cumulatively, where the measurements of the $\mathrm{GECO}_{2}$ started one week before the first harvest of tomatoes began. The fixed $\mathrm{CO}_{2}$ was expressed as gram $\mathrm{CO}_{2}$ per square meter of the cultivated 
net-acreage $\left(\mathrm{g} \mathrm{CO}_{2} \mathrm{~m}^{-2}\right)$. The $\mathrm{GECO}_{2}$ was specified as follows:

$$
\mathrm{GECO}_{2}=\frac{\mathrm{Q} \times \mathrm{DiffCO}_{2} \times \mathrm{p}}{29.93 \times \mathrm{ChA} \times \mathrm{T}_{A I R}}
$$

To determine the light conditions in the passively cooled greenhouse, the spatial light difference ratio between the reference GH and the collector GH was calculated. As such, 84 measuring points were located at a height of 4.60 meters for a uniform measuring distribution. The incoming light in both greenhouses was measured with PAR-sensors at the same measuring points and at the same time on a sunny day in October 2011. Subsequently, the spatial light difference ratio in the collector GH was derived, where zero is defined as $100 \%$ of the incoming light in the reference $\mathrm{GH}$. The results were expressed as percentage (\%).

\subsection{Calculation of the Energy Use Efficiency and Reduced Fuel Consumption}

The energy use efficiency is defined as the amount of energy required to produce one kg of marketable fruit and was expressed as $\mathrm{MJ} \mathrm{kg}^{-1}$. The calculations were performed cumulatively, where the respective tomato yield and the energy consumption of each greenhouse were used. In this context, variables such as the energy consumed (EC) for the circulation pumps (CP) and for heat pump processes (HP), the primary energy factor for electrical energy (PFEE) and the collector GH as heat producing system were considered to calculate the EUE for the collector GH (Equation 2). The latter means that the excess energy (EE) stored in the rain water tank was subtracted from the actual energy consumption in the collector GH, because the available energy could theoretically be used elsewhere. Regarding the reference GH, the EUE was calculated in consideration of the consumption of district heat (DH), the primary energy factor for district heat (PFDH) and excluding energy generation (Equation 3). The EUE was calculated as follows:

$$
\begin{gathered}
\mathrm{EUE}_{\text {collector } G H}=\frac{\left(\mathrm{EC}_{D H} \times \mathrm{PFDH}\right)+\left(\mathrm{EC}_{C P+H P} \times \mathrm{PFEE}\right)-(\mathrm{EE})_{0}}{\text { Total yield }} \\
\text { EUE }_{\text {reference } G H}=\frac{\left(\mathrm{EC}_{D H} \times \mathrm{PFDH}\right)_{0}}{\text { Total yield }}
\end{gathered}
$$

The EUE was plotted weekly from the first to the last harvest date. In this context, the energy consumption from planting to the first harvest date was added in equal amounts to each calculation of the EUE. An improved EUE exists when less energy is required for the same amount of tomato fruit.

To evaluate the possible reduction of the fuel consumption per kilogram produced tomatoes using a collector GH, the difference of the energy use efficiency between the collector and reference greenhouse was calculated at the end of the experiment. This result and the heating value of a variety of fuels were set in relation, in order to calculate the equivalent amount of the corresponding fuel and $\mathrm{CO}_{2}$ emissions produced by their combustion. The heating values of natural gas, coal, vegetable oils, heating oil and wood pellets, as well as their properties regarding $\mathrm{CO}_{2}$ release were used as reported by Ulbig and Hoburg (2002), Demirbas (2004), Fassinou et al. (2010), iwo (2012), Telmo and Lousada (2011) and using a special software program named GEMIS version 4.8 (GEMIS, 2010), respectively. Depending on the heating material, the saved fuel was either expressed as cubic metre or kilogram per kilogram tomatoes, whereas the reduced $\mathrm{CO}_{2}$ emission was displayed as kilogram $\mathrm{CO}_{2}$ per kilogram tomatoes.

\subsection{Statistical Analysis}

The effect of the $\mathrm{CO}_{2}$ fixation within the crop on the yield increase was evaluated with SPSS, package version 19.0. In this context, the linear correlation between these variables was calculated via linear regression analysis to obtain the coefficient of determination $\left(\mathrm{R}^{2}\right)$ and to test whether the slope $(\mathrm{m})$ in $\mathrm{y}=\mathrm{mx}+\mathrm{b}$ differs significantly $(\mathrm{p}<0.05)$ from zero. Comparisons regarding fruit yield and the number of fruit were calculated using t-tests $(\mathrm{p}<0.05)$. Asterisks or different small letters indicate significant differences. The mean variability is pointed out by the standard deviation $\left( \pm\right.$ ). All other calculations regarding $\mathrm{CO}_{2}$ fixation, energy distribution and EUE were calculated with EXCEL, package version 2010.

\section{Results and discussion}

\subsection{Generation of Energy Using a Solar Collector Greenhouse and Changes in Climate Conditions}

During the warm period, the energy caused by the transmitted solar radiation and water vapour was captured using a cooling fin system under the roof, which was connected to a reversible heat pump and a low temperature storage tank. The graphs in Figure 2 present the behaviour of the removed energy depending on the transmitted 
solar radiation for seven days during the summer period in 2011. On the fifth day of the recorded data, a maximum daily amount of energy $\left(11.5 \mathrm{MJ} \mathrm{m}^{-2}\right)$ was removed from the collector greenhouse, where a maximum cooling capacity of $368 \mathrm{~W} \mathrm{~m}^{-2}$ was measured. The calculations showed that a maximum collector efficiency factor of 0.7 was achieved on this day, when the removed total energy was considered in relation to the transmitted solar energy. Comparable results regarding cooling capacity and collector efficiency were reported by Grisey, Grasselly, Rosso, D’ Amaral, and Melamedoff (2011), who have used 9 FiWiHEx ${ }^{\circledR}$ heat exchanger. This type of cooling is referred to as active cooling, which requires high amounts of energy for ventilators, pumps and the cooling machine. In the present study, however, a passive cooling system only equipped with cooling pipes and a reversible heat pump was used. Therefore, the construction of the collector GH can be applied to reduce the energy costs compared with the FiWiHEx ${ }^{\circledR}$ system mentioned before. According to Eisenmann, Vajen, and Ackermann (2004), as well as Kumar and Prasad (2000), the collector efficiency factor of a thermal solar collector ranged between 0.7 and 0.9. Despite these higher values, the effectiveness of the installed system in the solar collector greenhouse is comparable to a thermal solar collector due to the fact that higher plate temperatures result in more heat losses, which lead to a lower value of the collector efficiency factor (approximately 0.5) of such systems. Based on an annual production of tomatoes, this value corresponds to the mean value obtained in the collector GH. In general, the captured total energy increased with increasing solar radiation $\left(\mathrm{R}^{2}=0.87\right.$ ) (Figure 2$)$. This result was caused by low ventilation, a high ambient temperature and higher levels of relative humidity. In relation to the total energy removal, the mean daily quantity of sensible heat energy and latent energy was $71 \%$ and $29 \%$, respectively. However, it was shown that the rate of latent energy can be increased to $44 \%$ when a dehumidification system combined with a cucumber crop is used (Campen \& Bot, 2002; Campen, Bot, \& de Zwart, 2003). Viewed over the year, a total amount of energy of $50 \%$ of the impinging solar radiation sum was collected with the solar collector greenhouse, although the emergency ventilation was frequently activated to avoid plant damage. In this context, it should be pointed out that a high energy removal in the closed operation mode is accompanied by high levels of temperature and relative humidity as shown in Figure 3. Based on the semi-closed operation mode in the collector $\mathrm{GH}$, a mean $\mathrm{RH}$ of approximately $92 \%$ was maintained during the production cycle, whereas the RH in the conventionally controlled greenhouse varied widely from $64 \%$ to $92 \%$ (Figure 3). Due to the later opening of the ventilation in the collector $\mathrm{GH}$, a higher mean temperature and mean $\mathrm{CO}_{2}$ concentration were reached compared to the reference GH. A maximum difference in the daily mean temperature $(2 \mathrm{~K})$ and $\mathrm{CO}_{2}$ concentration $(233 \mathrm{ppm})$ was measured in spring. However, the calculated levels of $\mathrm{RH}$, temperature and $\mathrm{CO}_{2}$ did not differ significantly during the autumn period, which was caused by cooler outside conditions and the associated ventilation set-point in the reference GH. These characteristics may influence the plant vigour, e.g., the occurrence of Botrytis (Heuvelink, Bakker, Marcelis, \& Raaphorst, 2008) and can complicate the working conditions for the employees, especially in summer time. Therefore, the challenge to producers is to learn how to work using the new system, including the use of precise measuring technologies, to control dew points and plant physiological processes. 


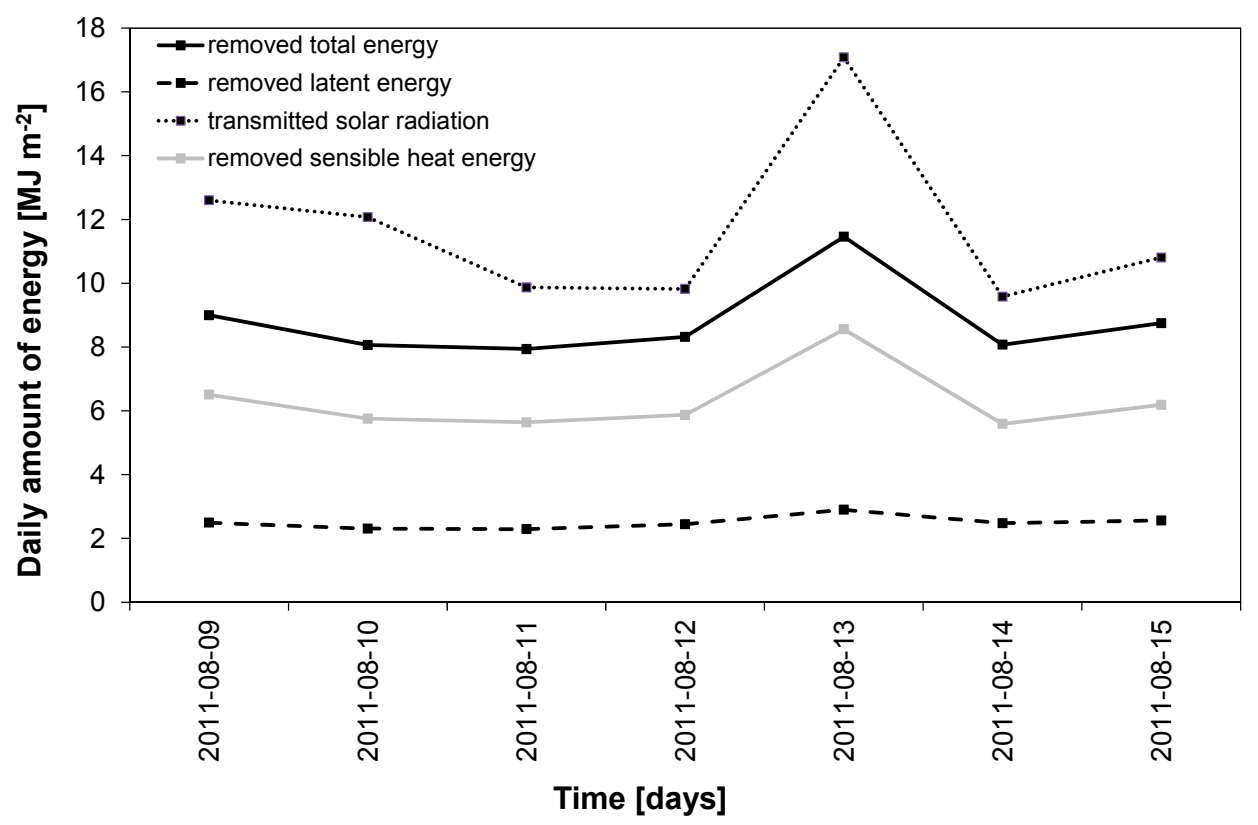

Figure 2. Collected energy dimensions depending on transmitted solar radiation

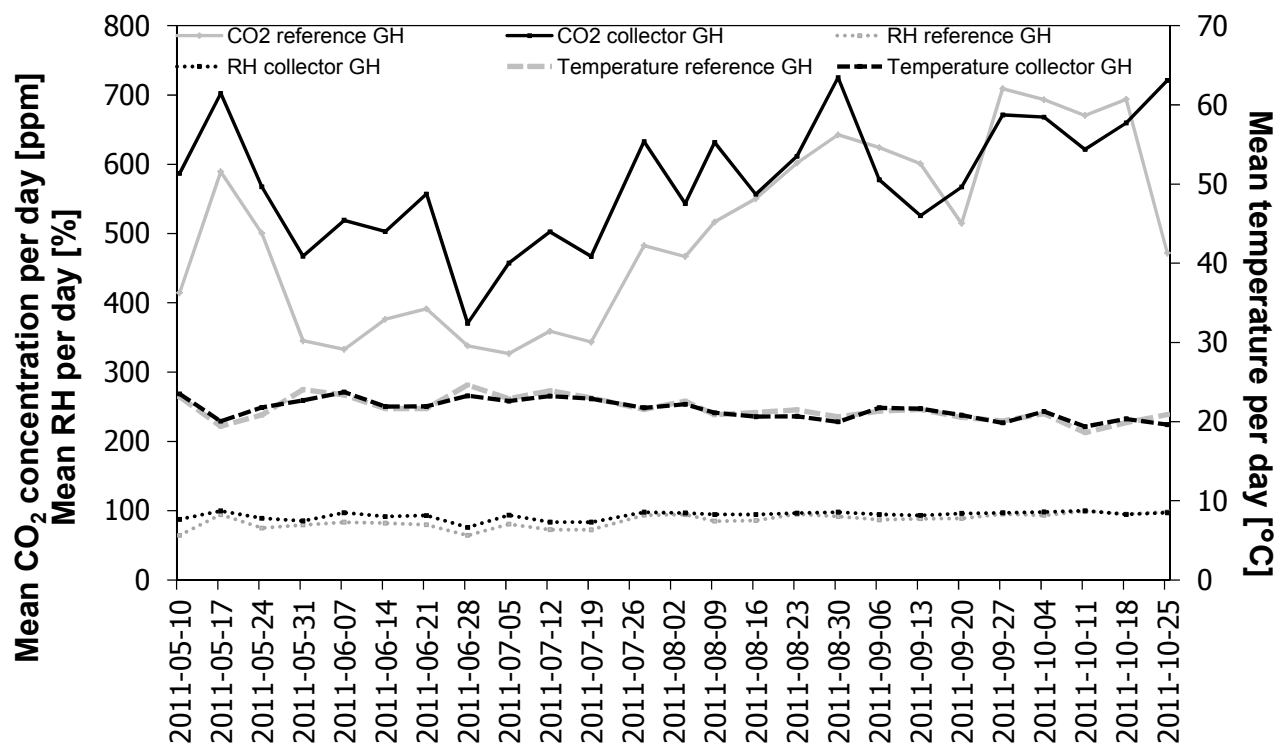

Harvest date

Figure 3. Effects of different cliamte control stratgies on relative humidity, temperature and $\mathrm{CO}_{2}$ concentration during harvest period

\subsection{Effects of Prevailing Climate Conditions in a Solar Collector Greenhouse on Fruit Yield and $\mathrm{CO}_{2}$ Fixation}

In comparison with the conventional climate control strategy, it was found that changing climate conditions caused by the collector GH - were responsible for a significantly increase in quantity of tomatoes (Figure 4). A maximum yield increase by $32 \%$ was achieved at the end of the experiments. This extra yield was attained, even though the mean light intensity in the collector GH was reduced by $11 \%$. This result was computed from the spatial light difference ratio as shown in Figure 5. The low values of these calculations were mainly induced due to the cooling fins and energy screens installed in the roof region of the collector $\mathrm{GH}$, where it meight be possible that probably $3 \%$ of the light was intercepted by the cooling fins as shown by Campen and Bot (2002). Light sinks especially occurred under the energy screens as detected at the measuring point one, four, seven, ten 
and twelve. Marcelis, Broekhuijsen, Meinen, Nijs, and Raaphorst (2006) reported that $1 \%$ less radiation results in $0.6 \%$ to $1.1 \%$ less production of tomatoes. These results were not confirmed in the present study as previously described. Rather, it might be possible that compensations for the light deficiency can be obtained by the optimisation of other climatic parameters, such as temperature, relative humidity and $\mathrm{CO}_{2}$ concentration, particularly in spring and summer. Based on the ventilation behaviour and associated changing climate conditions, it was demonstrated that the calculated $\mathrm{CO}_{2}$ fixation within the crop was increased by $77 \%$ compared to that observed in the reference GH (Figure 4). When a collector GH was used, $60 \%$ of the enriched technical $\mathrm{CO}_{2}$ was fixed within the crop, whereas this amount was reduced to approximately $35 \%$ by the influence of the reference situation. In this context, it is common in commercial practice that the $\mathrm{CO}_{2}$ enrichment remains switched on in greenhouses, although the ventilation is opened. Compared to this case, the operation mode of a semi-closed greenhouse leads to a reduction in $\mathrm{CO}_{2}$ emissions and costs of the technical $\mathrm{CO}_{2}$, because it can be kept longer closed. Furthermore, a significant correlation and a significantly increased slope compared with zero was found between the cumulative $\mathrm{CO}_{2}$ fixation and the total yield $\left(\mathrm{R}^{2}=0.89 ; \mathrm{m}=3.55, \mathrm{p}=0.000\right)$. Regarding photosynthetic activity, the results do not agree with those of other scientists. Besford, Ludwig, and Withers (1990), for instance, found that plants did not maintain a photosynthetic gain with longer-term $\mathrm{CO}_{2}$ enrichment at $1000 \mathrm{ppm}$. However, plants in this investigation were solely exposed to different $\mathrm{CO}_{2}$ concentrations, while the temperature and the relative humidity remained unchanged. Therefore, the evidence in the current study indicated that a combination of higher levels of temperatures, relative humidity and $\mathrm{CO}_{2}$ concentration in a semi-closed GH promoted photosynthesis, which resulted in an increased $\mathrm{CO}_{2}$ fixation and an associated increase in total yield. This total yield was characterized by high quality fruit consisting of a significantly increased number of marketable fruit (24\%) when compared with the reference plants. This means in detail that the number of A-fruit was increased and that of B-fruit was decreased by $45 \%$ and $8 \%$, respectively (Figure 6 ). Furthermore, the occurrence of BER-fruit was affected by the collector GH, because the number of these fruit was reduced by up to $83 \%$ in relation to that of BER-fruit formed under conventional conditions. It is assumed that the lower levels of RH in the reference GH led to high transpiration losses followed by a calcium deficiency in plant cells during the summer period. In this case, the BER-fruit can spread throughout the crop as shown by De Kreij (1996).

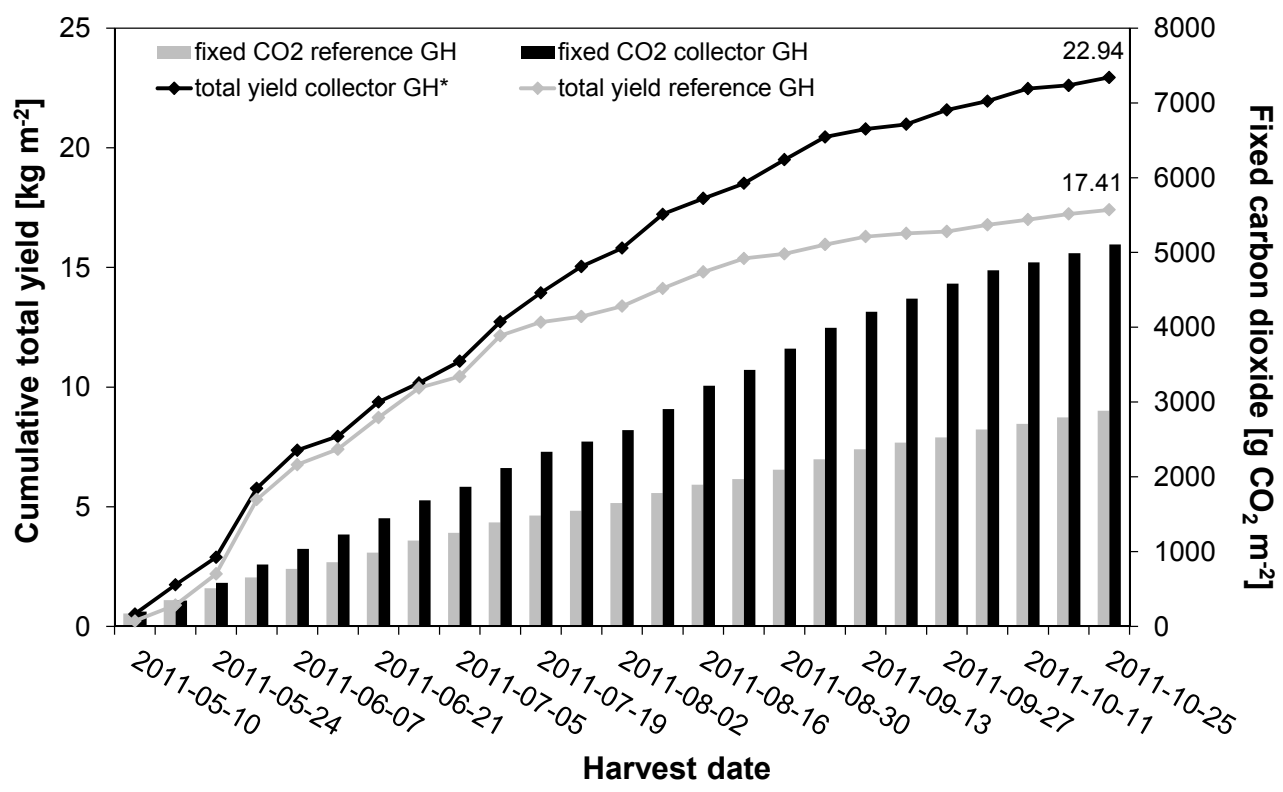

Figure 4. Effects of different climate control strategies on the cumulative total yield $(n=400)$ and carbon dioxide fixation within the crop. The total was tested using t-tests, where asterisks indicate significant differences in total yield at the end of the experiment $(\mathrm{p}<0.05)$ 


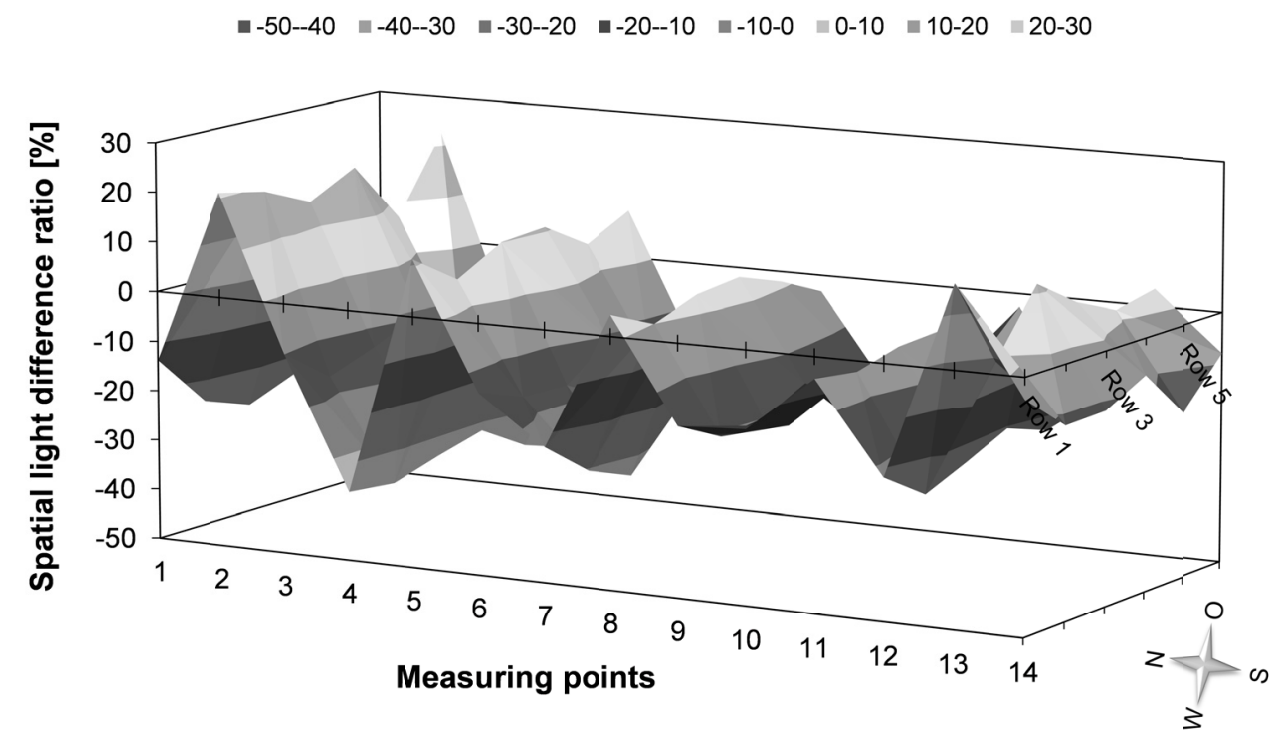

Figure 5. The spatial light difference ratio in the collector greenhouse versus reference greenhouse $(n=84)$. Zero is defined as $100 \%$ of the incoming light in the reference greenhouse

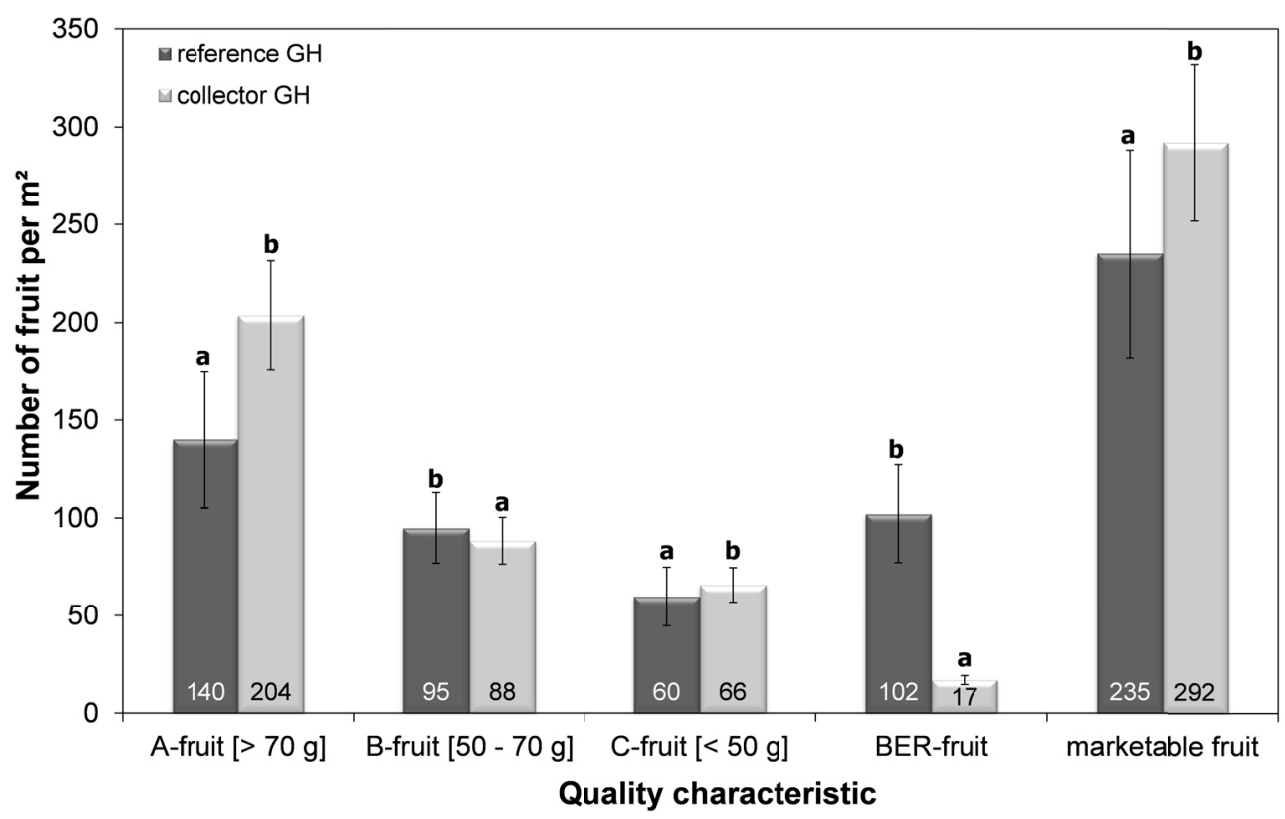

Figure 6. The effects of different climate control strategies on fruit quality $(n=400)$. The number of fruit was tested using t-tests, where small letters indicate significant differences in number of fruit at the end of the experiment $(\mathrm{p}<0.05)$

\subsection{Influence of a Solar Collector Greenhouse on the Energy Use Efficiency and Reduced Fuel Consumption}

The EUE is a useful tool to estimate the total energy use for greenhouse production. In the present study, the EUE for both greenhouses was approximately $40 \mathrm{MJ} \mathrm{kg}^{-1}$ produced tomatoes, when the excess energy stored in the rain water tank was not considered to calculate the EUE for the collector GH (data not shown). In contrast, the results elucidated that the EUE in the collector GH can be improved by $103 \%$ compared to the reference GH as consequence of the reuse of the stored energy. Based on the dimension of the cooling system in the collector 
GH and using the equation to calculate the EUE (Equation 2), an energy input of -1.41 MJ had to be applied in the collector GH, in order to produce one kilogram tomatoes (Figure 7). Therefore, an energy gain was achieved in the solar collector greenhouse at the end of the experiment (Figure 7). Comparable values were determined in Spain and in the tropics of Columbia as well (Elings et al., 2005; Medina, Cooman, Parrado, \& Schrevens, 2006). With respect to these countries, an EUE level of $1.97 \mathrm{MJ} \mathrm{kg}^{-1}$ and $1.11 \mathrm{MJ} \mathrm{kg}^{-1}$ was estimated, respectively, where this low energy input for crop production was a result of unheated greenhouses. However, the energy use efficiency in the collector GH was improved by means of the additional yield, collected solar energy throughout the year and strongly aluminized energy screens. Due to the energy screens, the energy demand decreased with increasing insulation up to 33\% (data not shown). Similar results were reported by Tantau (1998) and Bot et al. (2005) using thermal screens. Furthermore, the deteriorating energy use efficiency in the collector GH was assessed as a disadvantage, which was observed over the harvest period (Figure 7). This result was a consequence of the energy consumption for cooling processes in summer, whereas this procedure contributed to the fact that large amounts of energy were stored in the rain water tank. Especially in summer, there was an energy excess, which can be used primarily to cover the basic load for heating in other greenhouses or to provide subareas in greenhouses with luxury heat. The stored energy can also be delivered to sanitary facilities in the immediate vicinity or to postharvest processes, e.g., for drying of tomatoes. In this context, the collected heat can be directly applied via heat exchangers to fruit, because a low drying air temperature protects the quality of nutritional components in tomatoes (Hossain, Amer, \& Gottschalk, 2008). Moreover, the water containing in the low temperature storage tank had drinking water quality concerning microbiology criteria, although this was circulated in cooling and heating processes for a year. Neither Escherichia coli $(\leq 0$ most probable number 100 $\left.\mathrm{ml}^{-1}\right)$ nor coliform bacteria $\left(\leq 0\right.$ most probable number $\left.100 \mathrm{ml}^{-1}\right)$ were detected in this water. Therefore, it can be reused for watering without concern.

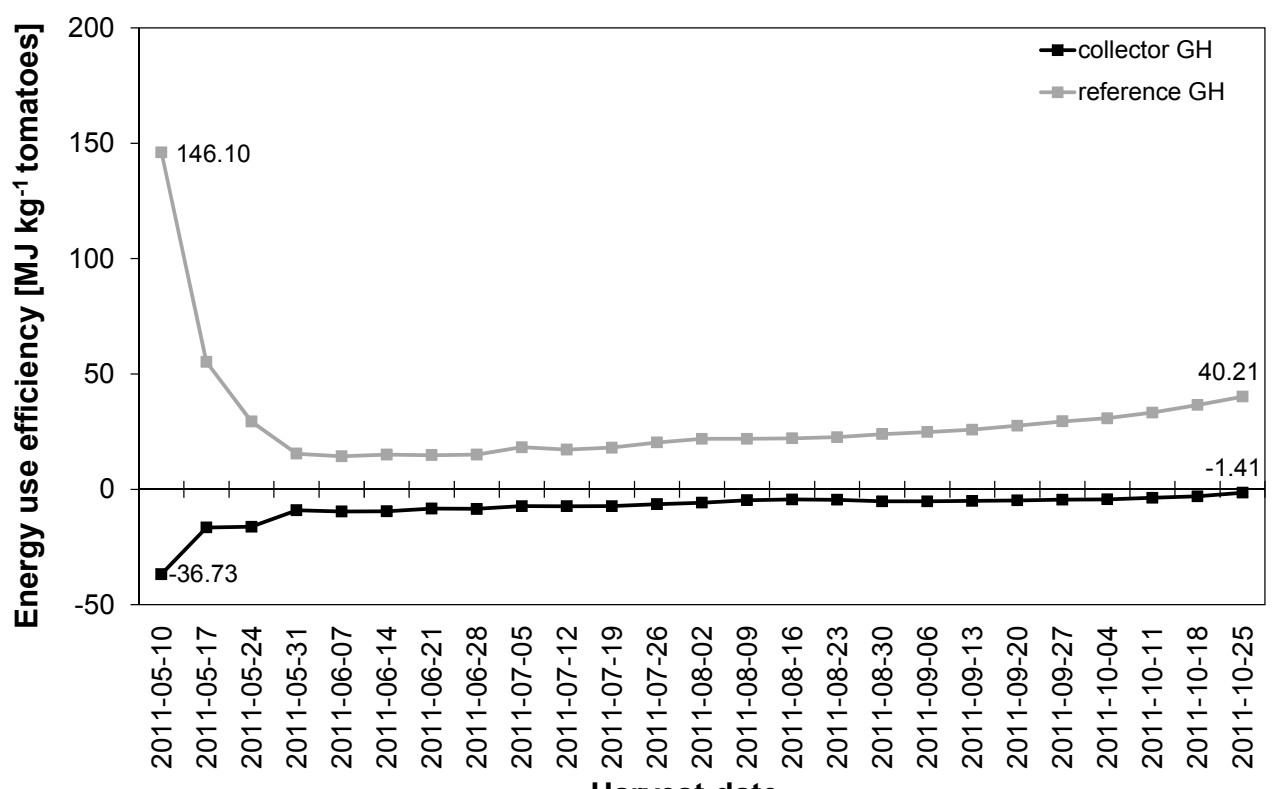

Harvest date

Figure 7. The weekly cumulative energy use efficiency depending on different operation modes of greenhouses

Finally, the energy saving per kilogram produced tomatoes in the collector GH is equivalent to the combustion of $1.04 \mathrm{~m}^{3}$ natural gas, $1.67 \mathrm{~kg}$ coal, $1.04 \mathrm{~kg}$ vegetable oil, $0.92 \mathrm{~kg}$ heating oil or $2.08 \mathrm{~kg}$ wood pellets when compared with the conventional tomato production (Figure 8). Hence, this technology can be utilized to reduce a substantial volume of $\mathrm{CO}_{2}$ emissions, whereby it is possible to produce tomato plants in a sustainable way. The equivalent reduced $\mathrm{CO}_{2}$ emission ranged between $2.32 \mathrm{~kg}$ and $4.18 \mathrm{~kg} \mathrm{CO}_{2}$ per kg produced tomatoes, where these data depend on the fuel used (Figure 8). 


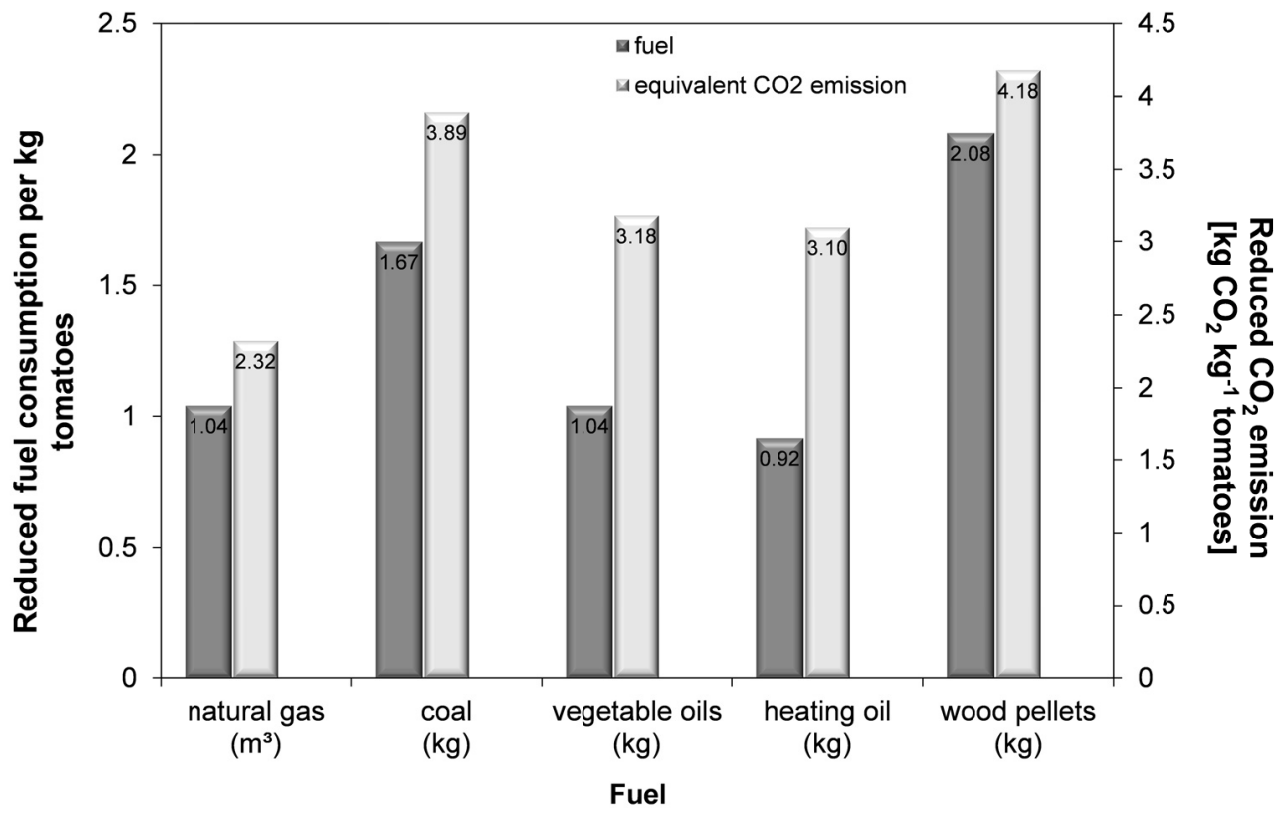

Figure 8. Several examples of a possible reduction of the fuel consumption per kilogram produced tomatoes in the collector greenhouse and fuel-related $\mathrm{CO}_{2}$ emissions released by their combustion

\section{Conclusion}

Due to the results, it was concluded that a semi-closed solar collector greenhouse can be recommended as agronomic approach to produce a high quantity of marketable tomatoes and additional energy, whereby the environment can be relieved. On an annual basis, a considerable amount of energy of the incoming solar radiation was captured using the cooling fin system. This energy can be reused for heating in cooler periods or provided for the heat export to other purchasers. Furthermore, the mean light interception of $11 \%$ caused by energy screens and cooling fins in the collector GH did not influence the yield adversely. The opposite was observed. It is obviously possible that a reduced ventilation opening and associated higher levels of temperatures, relative humidity and $\mathrm{CO}_{2}$ concentrations can compensate the light reduction over the year, leading to higher $\mathrm{CO}_{2}$ fixation and more yields. Nevertheless, a lower light interception by mounting parts (e.g., energy screens) should be sought in future projects, whereby possibly higher yield differences between both climate control strategies could be achieved. In this context, a combination of a solar collector and a conventional greenhouse area in a ratio of one to three is conceivable. As such, the excess energy may be provided for the conventional greenhouse production while the light reduction caused by cooling fins and additional energy screens is limited to the closed greenhouse area.

\section{Acknowledgement}

This feasibility study was funded by the Federal Ministry for Environment, Nature Conservation and Nuclear Safety and the Rentenbank managed by the Federal Ministry of Food, Agriculture and Consumer Protection with assistance of the Federal Agency for Agriculture and Food. We would like to thank all the scientists and student assistants of Division Biosystems Engineering.

\section{References}

Besford, R. T., Ludwig, L. J., \& Withers, A. C. (1990). The greenhouse effect: acclimation of tomato plants growing in high $\mathrm{CO}_{2}$, photosynthesis and ribulose-1, 5-bisphosphate carboxylase protein Journal of Experimental Botany, 41(229), 925-931. http://dx.doi.org/Doi 10.1093/Jxb/41.8.925

Bot, G. P. A. (2001). Developments in indoor sustainable plant production with emphasis on energy saving. Computers and Electronics in Agriculture, 30(1-3), 151-165. http://dx.doi.org/10.1016/s0168-1699(00)00162-9

Bot, G. P. A., Van de Braak, N., Challa, H., Hemming, S., Rieswijk, T., Von Straten, G., \& Verlodt, I. (2005). The solar greenhouse: State of the art in energy saving and sustainable energy supply. Acta Horticulturae, 
691, 501-508.

Campen, J. B., \& Bot, G. P. A. (2002). Dehumidification in greenhouses by condensation on finned pipes. Biosystems Engineering, 82(2), 177-185. http://dx.doi.org/10.1006/beng.2002.0058

Campen, J. B., Bot, G. P. A., \& de Zwart, H. F. (2003). Dehumidification of greenhouses at northern latitudes. Biosystems Engineering, 86(4), 487-493. http://dx.doi.org/10.1016/j.biosystemseng.2003.08.008

Dannehl, D. (2010). Gewächshaus-Eindeckmaterialien. Die Bedeutung der Lichtquantität und Lichtqualität in Tropenhäusern. Saarbrücken: VDM Verlag Dr. Müller.

De Gelder, A., Dieleman, J. A., Bot, G. P. A., \& Marcelis, L. F. M. (2012). An overview of climate and crop yield in closed greenhouses. Journal of Horticultural Science \& Biotechnology, 87(3), 193-202.

De Kreij, C. (1996). Interactive effects of air humidity, calcium and phosphate on blossom-end rot, leaf deformation, production and nutrient contents of tomato. Journal of Plant Nutrition, 19(2), 361-377.

Demirbas, A. (2004). Combustion characteristics of different biomass fuels. Progress in Energy and Combustion Science, 30(2), 219-230. http://dx.doi.org/10.1016/j.pecs.2003.10.004

Eisenmann, W., Vajen, K., \& Ackermann, H. (2004). On the correlations between collector efficiency factor and material content of parallel flow flat-plate solar collectors. Solar Energy, 76(4), 381-387. http://dx.doi.org/10.1016/j.solener.2003.10.005

Elings, A., Kempkes, F. L. K., Kaarsemaker, R. C., Ruijs, M. N. A., Van de Braak, N. J., \& Dueck, T. A. (2005). The energy balance and energy-saving measures in greenhouse tomato cultivation. Acta Horticulturae, 691(691), 67-74.

Esen, M., \& Yuksel, T. (2013). Experimental evaluation of using various renewable energy sources for heating a greenhouse. Energy and Buildings, 65, 340-351. http://dx.doi.org/10.1016/j.enbuild.2013.06.018

Fassinou, W. F., Sako, A., Fofana, A., Koua, K. B., \& Toure, S. (2010). Fatty acids composition as a means to estimate the high heating value (HHV) of vegetable oils and biodiesel fuels. Energy, 35(12), 4949-4954. http://dx.doi.org/DOI 10.1016/j.energy.2010.08.030

GEMIS. (2010). Global Emissions Model for Integrated Systems, 2013. Retrieved from http://www.iinas.org/gemis-download-de.html

Grisey, A., Grasselly, D., Rosso, L., D’ Amaral, F., \& Melamedoff, S. (2011). Using heat exchanger to cool and heat a closed tomato greenhouse: application in the south of France. Acta Horticulturae, 893, 405-411.

Heuvelink, E., Bakker, M., Marcelis, L. F. M., \& Raaphorst, M. (2008). Climate and yield in a closed greenhouse. Acta Horticulturae, 801, 1083-1092.

Hossain, M. A., Amer, B. M. A., \& Gottschalk, K. (2008). Hybrid Solar Dryer for Quality Dried Tomato. Drying Technology, 26(12), 1591-1601. http://dx.doi.org/10.1080/07373930802467466

Iwo. (2012). Das Plus an Informationen zum Produkt Heizöl EL (pp. 4-43). Hamburg: Institut für Wärme und Oeltechnik.

Kumar, A., \& Prasad, B. N. (2000). Investigation of twisted tape inserted solar water heaters - heat transfer, friction factor and thermal performance results. Renewable Energy, 19(3), 379-398. http://dx.doi.org/10.1016/S0960-1481(99)00061-0

Lansink, A. O., \& Bezlepkin, I. (2003). The effect of heating technologies on CO2 and energy efficiency of Dutch greenhouse firms. Journal of Environmental Management, 68(1), 73-82. http://dx.doi.org/10.1016/S0301-4797(02)00233-5

Lund, J. W., Freeston, D. H., \& Boyd, T. L. (2005). Direct application of geothermal energy: 2005 Worldwide review. Geothermics, 34(6), 691-727. http://dx.doi.org/10.1016/j.geothermics.2005.09.003

Marcelis, L. F. M., Broekhuijsen, A. G. M., Meinen, E., Nijs, E. M. F. M., \& Raaphorst, M. G. M. (2006). Quantification of the growtdh response to light quantity of greenhouse grown crops. Acta Horticulturae, 711, 97-103.

Medina, A., Cooman, A., Parrado, C. A., \& Schrevens, E. (2006). Evaluation of energy use and some environmental impacts for greenhouse tomato production in the high altitude tropics. Acta Horticulturae, 718, 415-422.

Ozkan, B., Fert, C., \& Karadeniz, C. F. (2007). Energy and cost analysis for greenhouse and open-field grape 
production. Energy, 32(8), 1500-1504. http://dx.doi.org/10.1016/j.energy.2006.09.010

Rout, U. K., Akimoto, K., Sano, F., Oda, J., Homma, T., \& Tomoda, T. (2008). Impact assessment of the increase in fossil fuel prices on the global energy system, with and without $\mathrm{CO} 2$ concentration stabilization. Energy Policy, 36(9), 3477-3484. http://dx.doi.org/10.1016/j.enpol.2008.05.030

Sanner, B., Karytsas, C., Mendrinos, D., \& Rybach, L. (2003). Current status of ground source heat pumps and underground thermal energy storage in Europe. Geothermics, 32(4-6), 579-588. http://dx.doi.org/10.1016/s0375-6505(03)00060-9

Schmidt, U., Schuch, I., Dannehl, D., Rocksch, T., Salazar Moreno, R., Rojano Aguilar, A., \& Lopez, I. (2013). Long time plant response measurements for yield prediction, water use and climate control optimization using gas exchange measurements in semi closed and ventilated greenhouses. Acta Horticulturae, submitted.

Tantau, H. J. (1998). Energy saving potential of greenhouse climate control. Mathematics and Computers in Simulation, 48(1), 93-101. http://dx.doi.org/10.1016/S0378-4754(98)00145-1

Telmo, C., \& Lousada, J. (2011). The explained variation by lignin and extractive contents on higher heating value of wood. Biomass \& Bioenergy, 35(5), 1663-1667. http://dx.doi.org/10.1016/j.biombioe.2010.12.038

Ulbig, P., \& Hoburg, D. (2002). Determination of the calorific value of natural gas by different methods. Thermochimica Acta, 382(1-2), 27-35. http://dx.doi.org/10.1016/S0040-6031(01)00732-8

WBGU. (2008). Welt im Wandel. Sicherheitsrisiko Klimawandel: Springer-Verlag, Berlin Heidelberg.

\section{Copyrights}

Copyright for this article is retained by the author(s), with first publication rights granted to the journal.

This is an open-access article distributed under the terms and conditions of the Creative Commons Attribution license (http://creativecommons.org/licenses/by/3.0/). 